\title{
The Apoptosis-1/Fas Protein in Human Systemic Lupus Erythematosus
}

\author{
Eduardo Mysler, Paolo Bini, Jörn Drappa, Paula Ramos, Steven M. Friedman, Peter H. Krammer, ${ }^{*}$ and Keith B. Elkon \\ The Hospital for Special Surgery, Cornell University Medical Center, New York 10021; and *Institute of Immunology and Genetics, \\ German Cancer Research Center, Heidelberg, D-6900 Germany
}

\begin{abstract}
Three independent mutations involving the apoptosis-1 (APO1)/Fas receptor or its putative ligand have led to lupuslike diseases associated with lymphadenopathy in different strains of mice. To determine whether humans with SLE also have a defect in this apoptosis pathway, we analyzed the expression of APO-1 on freshly isolated blood mononuclear cells and on lymphocytes activated in vitro using flow cytometry and the monoclonal antibody anti-APO-1. Significantly higher levels of APO-1 expression were detected on freshly isolated peripheral $\mathrm{B}$ cells and both $\mathrm{CD4}^{+}$and $\mathrm{CD8}^{+} \mathrm{T}$ lymphocyte populations obtained from lupus patients when compared with normal controls $(P<0.001)$. Almost $90 \%$ of the cells that stained positive for APO-1 also expressed the CD29 antigen, suggesting that APO-1 was upregulated after lymphocyte activation in vivo. No defect in APO-1 regulation was detected after activation of SLE T (with anti-CD3) or B (with Staphylococcus aureus Cowan 1 ) lymphocytes in the presence of IL-2 in vitro. Similarly, the anti-APO-1 antibody induced apoptosis in $74 \pm 5 \%$ of activated SLE T cells in vitro compared with $79 \pm 6 \%$ of the normal controls $(P>0.05)$. These results reveal that, while APO-1/ Fas may play an important role in the regulation of lymphocyte survival in SLE, no consistent defect in the expression or function of the receptor could be detected in these studies. (J. Clin. Invest. 1994. 93:1029-1034.) Key words: systemic lupus erythematosus • apoptosis • Apoptosis-1 / Fas • B lymphocytes • T lymphocytes
\end{abstract}

\section{Introduction}

Apoptosis- 1 (APO-1 $)^{1}$ is a $48-\mathrm{kD}$ cell-surface glycoprotein that signals certain lymphocytes to die by apoptosis upon ligation with the monoclonal anti-APO-1 antibody (1). APO-1 is a member of the nerve growth factor family of receptors that are characterized by an extramembranous segment comprising cysteine-rich domains, a single transmembrane domain, and a cytoplasmic region of various size (2). Nucleotide sequence analysis of cDNAs encoding APO-1 (3) and the Fas protein (4) has shown that these proteins are identical, although the epitopes targeted by the monoclonal anti-APO-1 and anti-Fas

Address correspondence to Keith Elkon, The Hospital for Special Surgery, 535 East 70th Street, New York, NY 10021.

Received for publication 27 September 1993.

1. Abbreviations used in this paper: APO-1, apoptosis-1; ESR, erythrocyte sedimentation rate; PSS, primary Sjögren's syndrome; SAC, Staphylococcus aureus Cowan strain 1; SLEDAI, SLE disease activity index.

J. Clin. Invest.

(c) The American Society for Clinical Investigation, Inc.

$0021-9738 / 94 / 03 / 1029 / 06 \$ 2.00$

Volume 93, March 1994, 1029-1034 antibodies have not been mapped. The precise role(s) of APO1 / Fas (hereafter referred to as APO-1) in immune regulation is not yet defined, but high levels of receptor expression in double-positive thymocytes ( 5 ) (the stage at which negative selection occurs) and in activated peripheral lymphocytes (1, 5-7) suggest that APO-1 plays a role in thymic selection as well as in peripheral tolerance.

Three apparently independent mutations involving the APO-1 receptor or its putative ligand have resulted in a lupuslike disease in different mouse strains (8-10). Although the massive lymphadenopathy which accompanies lupus in these strains is not typical of human SLE, individual cases resembling the murine disease have been reported (11), and doublenegative $T$ cells have been implicated in the generation of antiDNA antibodies in SLE (12). Furthermore, there is clear evidence that background genes influence the immunological abnormalities and clinical expression induced by the lpr gene (13) and that mild features of autoimmunity may be observed in certain mouse strains heterozygous for the APO-1 gene mutation (14). To explore the possibility that an abnormality of APO-1 may influence expression of SLE in humans, we analyzed the level of APO-1 receptor expression as well as the ability of the receptor to be upregulated and to signal apoptosis in the peripheral blood lymphocytes of SLE patients.

\section{Methods}

Patients. PBMC were obtained from the following groups (numbers in parentheses): SLE (23), RA (9), primary Sjögren's syndrome (PSS) (6), and normal individuals. All SLE and RA patients fulfilled the American College of Rheumatology criteria for these diseases $(15,16)$. PSS patients had keratoconjunctivitis sicca, xerostomia, and a positive lip biopsy in the absence of any other known autoimmune disease as described previously (17). Patients were selected randomly from the outpatient clinics at The Hospital for Special Surgery, except that patients taking cytotoxic drugs were excluded from the study. SLE disease activity was assessed by the SLE disease activity index (SLEDAI) (18). To ensure that daily variations did not introduce systematic errors in the data, patient and control PBMC were paired and studied on the same day under the same conditions.

Flow cytometry analysis and antibodies. PBMC were isolated from peripheral blood by Ficoll-Hypaque centrifugation as described previously (19). The following mAbs (and their antigen specificity) were used for staining: anti-APO-1 (APO-1 / Fas) (1); OKT3 (CD3) (20); 2H4-RD1 (CD45RA) (21); 4B4-RD1 (CDw29) (22); B4-RD1 (CD19) (23); Leu-3a (CD4) (24); and Leu-2a (CD8) (24). Mouse IgG1 (MOPC-21) and IgG3 (FLOPC-21) isotype control mAbs were obtained from Sigma Chemical Co. (St. Louis, MO). Polyclonal secondary antibodies (conjugated to either FITC or phycoerythrin) were: goat anti-mouse IgG (absorbed for reactivity against human immunoglobulins), donkey anti-human IgM, rabbit anti-mouse IgG-Fc (Jackson ImmunoResearch Laboratories, Inc., West Grove, PA).

Flow cytometry analysis was performed on a cytofluorograph (IIs 50H; Ortho Diagnostic Systems Inc., Westwood, MA) and a cell sorting computer system (model 2151; Ortho Diagnostic Systems Inc.) as described previously (19). APO-1 expression on PBMC was detected 
by incubation of the cells with saturating amounts of anti-APO-1 or the isotype control $\mathrm{mAb}$ followed by FITC goat anti-mouse IgG. APO1 expression was quantified by analyzing at least 5,000 cells on the flow cytometer using the histogram obtained with the isotype control mAb to define the negative marker. Dead cells and debris were excluded from analysis by selective gating based on anterior and right angle scatter, and data were displayed on a log scale of increasing green or red fluorescence intensity. Two-color staining was performed as above except that both phycoerythrin- and FITC-conjugated second antibodies were used.

Lymphocyte culture and activation in vitro. PBMC were cultured ( 2 $\times 10^{6}$ cells $/ \mathrm{ml}$ ) in complete medium comprising RPMI 1640 medium supplemented with $10 \%$ FCS (both from JRH Biosciences, Lenexa, $\mathrm{KS}), 2 \mathrm{mM}$ L-glutamine, $100 \mathrm{U} / \mathrm{ml}$ penicillin, $100 \mu \mathrm{g} / \mathrm{ml}$ streptomycin, and $0.25 \mu \mathrm{g} / \mathrm{ml}$ amphotericin B in 24-well, flat-bottomed plates (Falcon Labware, Becton Dickinson \& Co., Lincoln Park, NJ). The cells were maintained for up to $6 \mathrm{~d}$ at $37^{\circ} \mathrm{C}$ in a humidified atmosphere in $5 \% \mathrm{CO}_{2}$. The following were used for $\mathrm{T}$ cell activation: anti-CD3 (1:5,000 dilution of ascites), and recombinant human IL-2 (100 IU/ ml) (provided by Maurice Gately, Hoffmann-La Roche Inc., Nutley, $\mathrm{NJ})$ or PHA $(10 \mu \mathrm{g} / \mathrm{ml})$.

B cells were isolated by negative selection as described (25). Briefly, $T$ cells were depleted by rosetting with neuraminidase-treated sheep red blood cells followed by removal of residual cells with anti-CD3-coated magnetic beads. Flow cytometry analysis revealed $<5 \% \mathrm{~T}$ cell contamination of the resulting B cell population. Since Staphylococcus aureus Cowan strain 1 (SAC) and IL-2 have previously been shown to upregulate APO-1 expression (26), $2 \times 10^{6} \mathrm{~B}$ cells/well were activated by incubation with $0.02 \%$ (final concentration) heat-killed SAC (Calbiochem-Nova biochem, San Diego, CA) in the presence of IL-2 (100 $\mathrm{IU} / \mathrm{ml})$.

Apoptosis induction and assays. After the isolation of the cells or at varying time points after initiation of the cultures $2 \times 10^{6}$ cells were cultured together with $1 \mu \mathrm{g} / \mathrm{ml}$ of either IgG3 anti-APO-1 or the isotype control $\mathrm{mAb}$ together with the affinity-purified rabbit anti-mouse IgG $(0.8 \mu \mathrm{g} / \mathrm{ml})$ to optimize cross-linking as described (27). Cultures were continued for an additional $12 \mathrm{~h}$ after which cell viability was determined by trypan blue exclusion and $\left[{ }^{3} \mathrm{H}\right]$ thymidine incorporation. Qualitative analysis of apoptosis was performed by a minor modification of the DNA fragmentation assay (28). Briefly, $2 \times 10^{6}$ cells were lysed in a buffer containing $10 \mathrm{mM}$ Tris, pH 7.4, $5 \mathrm{mM}$ EDTA, and $0.5 \%$ sarkosyl. Protein and RNA were digested with proteinase $K$ and DNase-free RNase, respectively, and the DNA was extracted with phenol/chloroform. The DNA was analyzed by electrophoresis on a $2 \%$ agarose gel and was stained with ethidium bromide.

Serology. The erythrocyte sedimentation rate (ESR) was determined by the Westergren method. Antinuclear antibody levels were quantified on Hep-2-coated dipsticks (BioWhittaker, Inc., Walkersville, MD) using a fluorimeter (International Diagnostic Technologies, Santa Clara, CA). Anti-DNA antibodies were quantified using slides coated with Crithidia lucilae (Wampole Laboratories, Cranbury, NJ) and were measured on a visual scale from 0 to $4+$.

Statistical analysis. Differences between the means were compared by Student's $t$ test (for parametric data) or by the Mann-Whitney rank sum test (for nonparametric data). Correlations were analyzed by linear regression (for parametric data) or by the Spearman rank correlation coefficient (for nonparametric data).

\section{Results}

APO-1 expression on freshly obtained PBMC. To minimize any day to day variation in flow cytometry analysis of APO-1 expression, the percentage of cells expressing APO- 1 in the patient population was expressed as a subtraction index (APO-1 expression on the patient's cells - APO-1 expression on the normal control's cells). As shown in Fig. 1, the percentage of cells expressing APO-1 was significantly higher on PBMC ob-

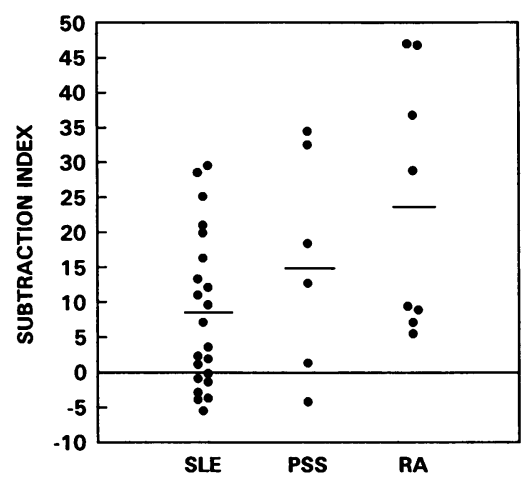

Figure 1. Expression of APO-1 on freshly isolated PBMC. PBMC obtained from SLE patients and disease controls (PSS and RA) were analyzed for the expression of APO-1 by flow cytometry using the mAb anti-APO- 1 . The results are expressed as the subtraction index (APO-1 expression on the patient's

cells - APO-1 expression on the paired normal control's cells). The levels of APO-1 expression on PBMC obtained from patients with SLE and with RA were statistically significantly higher $(P<0.001$ and $P<0.01$, respectively) and from patients with PSS were of borderline statistical significance $(P=0.05)$ when compared with the levels of the paired normal controls.

tained from SLE patients $(9 \pm 11)$ compared with normal controls (by definition, 0$)(P<0.001)$. When the percentage of cells expressing APO-1 was compared directly, the differences were also significant (SLE, $34 \pm 17$ and normal controls, $25 \pm 13$ $[P<0.001])$. Increased expression of APO-1 was also noted in patients with RA and PSS compared with normal controls, although the difference between PSS and normal controls was borderline (presumably because of the small numbers of patients tested) (Fig. 1).

Since APO-1 expression has been shown to be increased on activated lymphocytes ( $1,5-7$, and see below), correlations between the percentage of cells expressing APO-1 and a predominantly clinical index (the SLEDAI) as well as between individual serological indices of disease activity were examined. As shown in Fig. 2, no significant correlations between APO-1 expression and either clinical or serologic parameters of disease activity were observed $(P>0.05$ for all analyses $)$.

$A P O-1$ expression on lymphocyte populations. To determine which lymphocyte populations accounted for the increase in APO-1 expression, two-color flow cytometry with anti-APO-1 and mAbs specific for T (anti-CD3) or B (antiCD19) cells was performed. As shown in Table $I$, a higher proportion of SLE T cells $(46 \pm 14)$ compared with B cells (22 \pm 12 ) expressed APO-1. As observed for whole PBMC, the percentages of SLE T and B cells expressing APO- 1 were significantly greater than those observed in normal controls $(P$ $<0.05)$. To define which $\mathrm{T}$ cell subpopulations expressed APO-1, two-color flow cytometry was performed with antiAPO-1 and mAbs specific for either CD4, CD8, CD45, or CD29. As shown in Table I, APO-1 was expressed on both $\mathrm{CD}^{+}$and $\mathrm{CD}^{+} \mathrm{T}$ cells, but the percentage of cells expressing APO- 1 was relatively greater for $\mathrm{CD} 8^{+}$compared with $\mathrm{CD} 4^{+}$ cells ( 2.2 vs 1.5 times the normal controls, respectively). As also shown in Table I, almost all of the SLE T cells expressing APO-1 displayed the CD29 (activated) rather than the CD45RA (naive) phenotype.

APO-1 expression on lymphocytes activated in vitro. To determine whether SLE lymphocytes could be induced to upregulate APO-1 expression after activation in vitro, $T$ cells were stimulated with anti-CD3 and IL-2, and B cells were activated by SAC and IL-2 as described in Methods. Within $4 \mathrm{~d}$ after T 
A

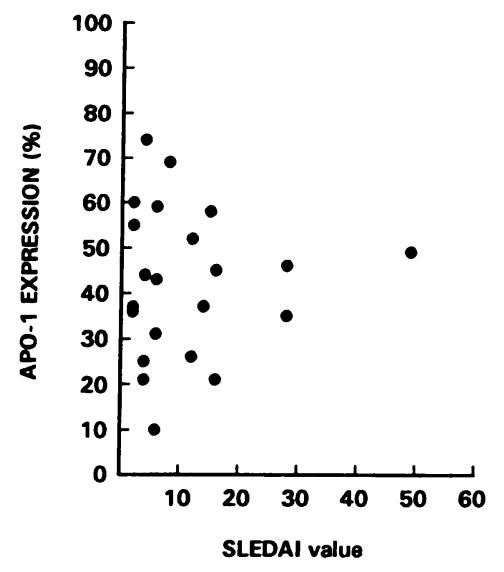

C

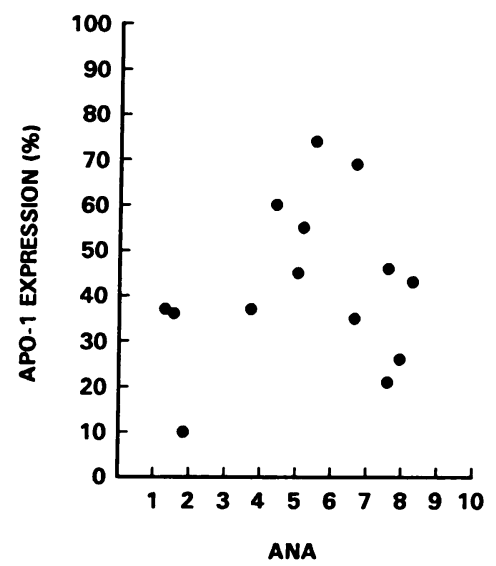

B

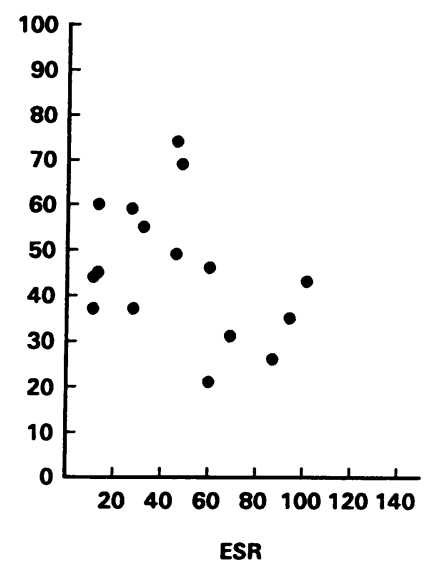

D

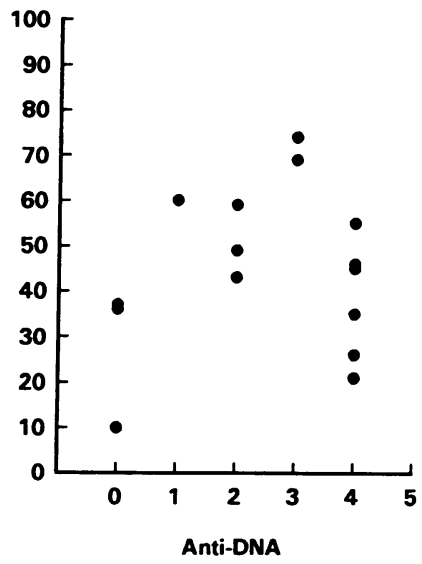

Figure 2. Relationship between APO-1 expression and markers of SLE disease activity. Expression of APO-1 on PBMC was determined as in Fig. 1 and was correlated with a composite score of disease activity, the SLEDAI $(A)$ (18). APO-1 was also correlated with individual serological parameters: the erythrocyte sedimentation rate $(B)$, antinuclear (ANA $[C])$, and antiDNA $(D)$ levels. There was no significant association between APO-1 expression and any of these parameters of disease activity $(P>0.05)$. cell (Fig. $3 A$ ) or B cell activation (Fig. $3 B$ ), APO-1 expression increased to $>90 \%$ in both SLE and control cells. No significant differences between SLE and controls were observed with respect to the kinetics or intensity of APO-1 cell-surface expression, or to the percentage of APO-1-positive cells after activation (Fig. 3). Similar findings were observed when SLE T cells were activated with PHA (not shown).

Induction of lymphocyte apoptosis. Recent studies have shown that, although peripheral $\mathrm{T}$ cells from normal individ-

Table I. Distribution of APO-1 on Lymphocyte Populations Obtained from Patients with SLE and from Normal Controls

\begin{tabular}{lcccccc}
\hline & $\mathrm{CD} 3$ & $\mathrm{CD} 19$ & $\mathrm{CD} 4$ & $\mathrm{CD} 8$ & $\mathrm{CD} 29$ & $\mathrm{CD} 45 \mathrm{RA}$ \\
\hline Normal & $28 \pm 7^{*}$ & $10 \pm 3^{*}$ & $38 \pm 8^{*}$ & $24 \pm 7^{\ddagger}$ & $72 \pm 21$ & $26 \pm 21$ \\
$n$ & 5 & 7 & 8 & 8 & 7 & 7 \\
SLE & $46 \pm 14^{*}$ & $22 \pm 12^{*}$ & $57 \pm 18^{*}$ & $54 \pm 22^{\ddagger}$ & $88 \pm 10$ & $21 \pm 10$ \\
$n$ & 11 & 7 & 8 & 8 & 5 & 5 \\
\hline
\end{tabular}

${ }^{*} P<0.05$. ${ }^{\ddagger} P<0.01$. uals upregulate APO- 1 expression within $2 \mathrm{~d}$ after activation, the cells only become susceptible to apoptosis at days 5 and 6 (29). To determine whether the APO-1 receptor was functional in SLE lymphocytes, $T$ cells activated with anti-CD3 and IL-2 for $6 \mathrm{~d}$ were induced to undergo apoptosis with the IgG3 anti-APO-1 mAb. As shown in Fig. 4, when $>90 \%$ of cells expressed APO-1, 74 $\pm 5 \%$ SLE T cells exposed to the APO-1 $\mathrm{mAb}$ and to cross-linking anti-mouse antibodies died. This percentage was not significantly different compared with the normal controls $(79 \pm 6 \%)(P>0.05)$. No cell death was induced with the cross-linking antibody alone (not shown ). Analysis of thymidine incorporation $5 \mathrm{~d}$ after $\mathrm{T}$ cell activation confirmed these findings (cells from SLE and normal individuals incubated with the control mAb: 31,612 $\pm 11,814$ and $56,246 \pm 21,490 \mathrm{cpm}$, respectively, and cells exposed to antiAPO-1 and cross-linking antibodies: $2,368 \pm 826$ and 2,783 $\pm 1,549$ cpm, respectively). Analysis of the DNA released from the nuclei of the cells exposed to anti-APO-1 revealed the 200-bp DNA ladder characteristic of apoptosis (Fig. 5).

Since a greater percentage of freshly isolated SLE lymphocytes expressed APO-1, the effect of exposure of these cells to 

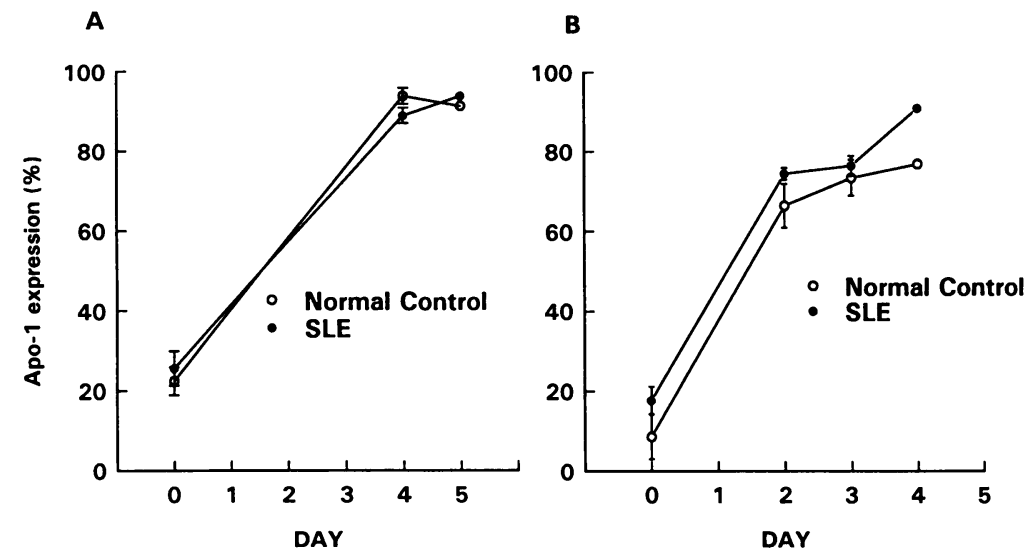

Figure 3. APO-1 expression on lymphocytes activated in
vitro. $(A) 2 \times 10^{6}$ PBMC were cultured in the presence
of the anti-CD $3 \mathrm{mAb}$ and IL-2 $(100 \mathrm{IU} / \mathrm{ml})$ for $5 \mathrm{~d}$. At
days 0,4 , and 5 , T cells were analyzed for APO-1 expres-
sion by two-color flow cytometry. The mean \pm SD of
studies on five different SLE patients and normal controls
is shown. $(B)$ Peripheral B cells were isolated as described
in Methods and were incubated with $0.02 \%$ SAC and
IL-2 $(100 \mathrm{IU} / \mathrm{ml})$ for $4 \mathrm{~d}$. B cells were analyzed for
APO- 1 expression on days $0,2,3$, and 4 by two-color flow
cytometry. The mean \pm SD of studies on four different
SLE patients and normal controls is shown.

the anti-APO-1 mAb was determined on total PBMC and on isolated B cells. As shown in Table II, no differences in cell viability were observed between SLE cells exposed to antiAPO-1 and the control mAb or between cells obtained from SLE patients and the healthy controls. Induction of apoptosis of SLE B cells activated in vitro could not be tested because of insufficient numbers of B cells recovered at day 5 of culture.

\section{Discussion}

SLE is a disease characterized by the production of autoantibodies directed against protein and nucleoprotein complexes. The profile of autoantibodies in this disease suggests that tolerance to multiple unrelated antigens is lost (for review see reference 30). To determine whether humans with SLE have a defect in APO-1 expression, regulation, or function, we quantified these parameters in patients with SLE and other systemic autoimmune diseases. In contrast to $\mathrm{MRL} / l p r$ mice $(5,8)$, the percentage of PBMC expressing APO-1 was significantly higher in SLE compared with normal controls. Increased expression was evident in B and T lymphocytes and in both of the major T cell subpopulations, CD4 and CD8. Since APO-1 is upregulated after in vitro activation of lymphocytes by mitogens or antigen receptor ligation $(1,5-7)$ and increased APO-1 expression was also observed in other systemic autoimmune disorders, the increase in expression in patients with SLE most likely reflects in vivo lymphocyte activation. In normal individ-

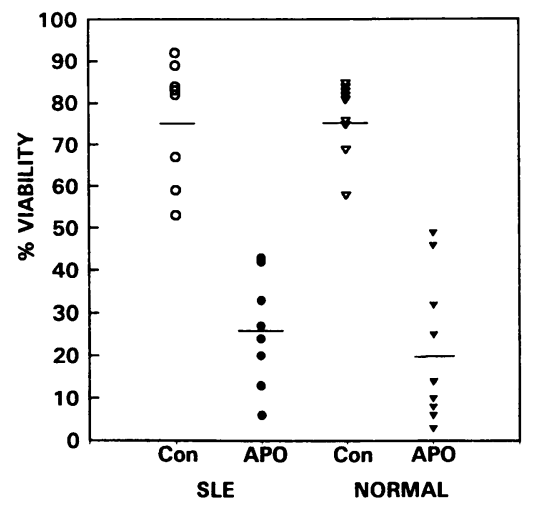

Figure 4. Induction of apoptosis of SLE lymphocytes in vitro. $5 \mathrm{~d}$ after the activation of $T$ cells with anti-CD3 and IL-2 (Fig. 3), $2 \times 10^{6}$ cells were incubated with $1 \mu \mathrm{g} / \mathrm{ml}$ of either control mAb (Con) or anti-APO-1 $\mathrm{mAb}$ $(A P O)$ and $0.8 \mu \mathrm{g} / \mathrm{ml}$ of rabbit anti-mouse IgG. Viability of the cells was determined 12 $h$ later by trypan blue exclusion. The mean value in each group is shown by a horizontal line. uals the CD45RA and CD45RO antigens mark naive and memory (previously activated) T cells, respectively (31). However, despite evidence for $\mathrm{T}$ cell activation in SLE, some $\mathrm{T}$ cell activation markers (e.g., MHC class II and the $\beta$ - 1 integrin, CD29) are increased whereas others (e.g., the IL-2 receptor and CD45RO) are not (for review see reference 32 ). As has been observed in normal individuals (33), APO-1 expression was detected almost exclusively in the (previously) activated $\mathrm{T}$ cell subset in SLE patients, thus supporting the concept that the increased APO-1 expression reflects lymphocyte activation. However, the lack of significant correlations with the composite index of disease activity, the SLEDAI, or with other serological parameters of activity indicates that the relationship between APO-1 expression and lymphocyte activation is complex.

Whereas previous studies of SLE T cells have shown that MHC class II is preferentially expressed on $\mathrm{CD}^{+} \mathrm{T}$ cells (34,

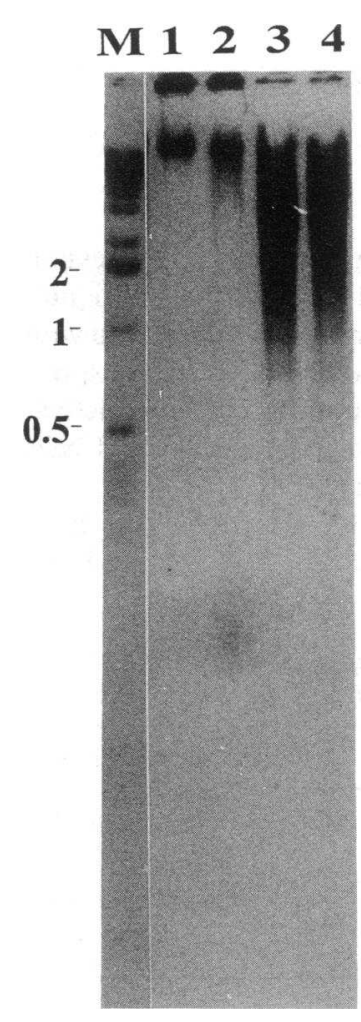

Figure 5. APO-1-induced apoptosis of SLE T cells. Apoptosis of activated $T$ cells was induced as in Fig. 4, and the released DNA isolated by phenol/chloroform extraction (28). The DNA was subjected to electrophoresis on a $2 \%$ agarose gel, was stained with ethidium bromide, and was photographed using a videoimager as described (44). DNA released from the lymphocytes incubated with either the control (lanes 1 and 2) or anti-APO-1 (lanes 3 and 4) mAb obtained from one representative SLE patient (lanes 1 and 3 ) and a normal control (lanes 2 and 4 ) are shown. The size markers (kb) are shown in lane $M$. The stained bands appear black since the image was obtained in the reverse mode. 
Table II. Viability of Freshly Isolated Total PBMC and of B Cells Obtained from SLE Patients and Normal Individuals after Exposure to the Anti-APO-1 Antibody

\begin{tabular}{llllll}
\hline & \multicolumn{2}{c}{ PBMC } & & \multicolumn{2}{c}{ B cells } \\
\cline { 2 - 3 } \cline { 6 - 6 } & Anti-APO-1 & Control & & Anti-APO-1 & Control \\
\hline SLE & $94 \pm 7$ & $91 \pm 4$ & & $96 \pm 2$ & $94 \pm 4$ \\
Normal & $90 \pm 9$ & $91 \pm 6$ & & $90 \pm 9$ & $93 \pm 10$ \\
& & & & & \\
\hline
\end{tabular}

$2 \times 10^{6}$ freshly isolated cells (see Methods) were incubated with either $1 \mu \mathrm{g} / \mathrm{ml}$ of anti-APO- 1 or isotype control mAb together with a crosslinking anti-mouse IgG for $16 \mathrm{~h}$ at $37^{\circ} \mathrm{C}$. Viability was assessed by trypan blue exclusion.

35), the relative increase in APO-1 expression in SLE T cells was greater in the $\mathrm{CD}^{+}$compared with the $\mathrm{CD} 4^{+}$subpopulation. Since the presumptive APO-1 ligand has been reported to be involved in $\mathrm{Ca}^{2+}$-independent $\mathrm{T}$ cell-mediated cytotoxicity (36), it will be important to determine whether the disproportionate increase in APO- 1 expression on $\mathrm{CD}^{+}$cells is associated with expression of the APO-1 ligand which may promote tissue injury by APO- $1^{+} \mathrm{CD} 8^{+} \mathrm{T}$ cells in SLE. Alternatively, Linker-Israeli et al. (37) have shown that $\mathrm{CD}^{+} \mathrm{T}$ cells are necessary for spontaneous IgG production by SLE B cells in vitro and have suggested that the $\mathrm{CD} 8^{+} \mathrm{T}$ cells in SLE may perform an unusual helper function due to abnormal cytokine production. In either event, it is likely that the greater than twofold increase in the number of $\mathrm{CD}^{+} \mathrm{T}$ cells expressing APO-1 marks a functionally important subset in SLE.

Since the majority of SLE patients had normal or increased levels of APO-1, we examined the ability of SLE lymphocytes to upregulate APO-1 expression and to signal cell death. No defect could be detected in APO-1 expression after mitogen or receptor stimulation of SLE lymphocytes, although the stimuli and conditions for in vitro testing were not exhaustive. Similarly, SLE T lymphocytes could be induced to undergo apoptosis after activation and exposure to the anti-APO-1 antibody as has been observed in normal lymphocytes $(6,7)$. Although these findings do not exclude a role for APO-1 in the etiology of SLE, they suggest that defects in the receptor and the signaling pathway are not common features in SLE patients and that the pathway for anti-APO-1-mediated apoptosis is intact in the patients tested. These findings do not address whether the APO-1 ligand is abnormal nor whether the authentic APO-1 ligand signals apoptosis appropriately in SLE lymphocytes since the human ligand has not yet been identified. Finally, it is possible that environmental stimuli such as radiation, toxins, or virus infection allow autoreactive cells to survive (do not induce apoptosis under the appropriate circumstances) in SLE, whether or not APO-1 is involved.

SLE patients, especially those with active disease, have a lymphopenia which can effect both CD4 and CD8 T cell populations (for review see reference 38). Although the lymphopenia may be explained, in part, by antilymphocyte autoantibodies, a partial depletion of $\mathrm{T}$ cells has been observed in the absence of detectable anti-T cell antibodies (39). Recently, it has been shown that both $\mathrm{CD}^{+}$and $\mathrm{CD}^{+}{ }^{+} \mathrm{T}$ cells from patients with AIDS are abnormally sensitive to activation-induced apoptosis $(40,41)$, and it has been suggested that this phenomenon may be partly responsible for lymphopenia in this disease $(40,41)$. Since the APO-1 pathway appears to be functional in SLE lymphocytes activated in vitro, it is possible that the increased expression of APO-1 results in enhanced susceptibility to apoptosis and subsequent lymphopenia in vivo. However, the failure to induce apoptosis of freshly isolated SLE PBMC or of B cells indicates that, if APO-1 is responsible for lymphopenia in SLE, apoptotic cells are rapidly removed in vivo. How autoantibodies, lymphokines, or possible virus infection (40-42) contribute to the balance of activation, survival, and death of SLE lymphocyte populations, and the roles of other molecules controlling apoptosis (43), remain vitally important areas for further investigation.

\section{Acknowledgments}

We thank Dr. Norman Talal for providing patients with PSS, Dr. Mary K. Crow for helpful discussions, Carl Triscari for assistance with flow cytometry, and Dr. Margaret Peterson for statistical advice.

This work was supported by grants AR-38915, P50 AR-425888, and AI-32634 from the National Institutes of Health, Bethesda, MD, and by Tumorzentrum, Heidelberg, Germany. P. Ramos is a recipient of the Fondo de Investigaciones Sanitarias, Ministerio de Sanidad de España.

\section{References}

1. Trauth, B. C., C. Klas, A. M. J. Peters, S. Matzku, P. Möller, W. Falk, K.-M. Debatin, and P. H. Krammer. 1989. Monoclonal antibody-mediated tumor regression by apoptosis. Science (Wash. DC). 245:301-305.

2. Mallet, S., and A. N. Barclay. 1991. A new superfamily of cell surface proteins related to the nerve growth factor receptor. Immunol. Today. 12:220 223.

3. Oehm, A., I. Behrmann, W. Falk, M. Pawlita, G. Maier, C. Klas, M. LiWeber, S. Richards, J. Dhein, B. C. Trauth et al. 1992. Purification and molecular cloning of the APO-1 cell surface antigen, a member of the tumor necrosis factor/ nerve growth factor receptor superfamily. Sequence identity with the Fas antigen. J. Biol. Chem. 267:10709-10715.

4. Itoh, N., S. Yonehara, A. Ishii, M. Yonehara, S.-I. Mizushima, M. Sameshima, A. Hase, Y. Seto, and S. Nagata. 1991. The polypeptide encoded by the cDNA for human cell surface antigen Fas can mediate apoptosis. Cell. 66:233243.

5. Drappa, J., N. Brot, and K. B. Elkon. 1993. The Fas protein is expressed at high levels on double positive thymocytes and activated mature $T$ cells in normal but not MRL/lpr mice. Proc. Natl. Acad. Sci. USA. 90:10340-10344.

6. Owen-Schuab, L. B., S. Yonehara, W. L. Crump, and E. A. Grim. 1992. DNA fragmentation and cell death is selectively triggered in activated human lymphocytes by Fas antigen engagement. Cell. Immunol. 140:197-205.

7. Miyawaki, T., T. Uehara, R. Nibu, T. Tsuji, A. Yachie, S. Yonehara, and N. Taniguchi. 1992. Differential expression of apoptosis-related Fas antigen on lymphocyte subpopulations in human peripheral blood. J. Immunol. 149:37533758.

8. Watanabe-Fukunaga, R., C. I. Brannan, N. G. Copeland, N. A. Jenkins, and S. Nagata. 1992. Lymphoproliferation disorder in mice explained by defects in Fas antigen that mediates apoptosis. Nature (Lond.). 356:314-317.

9. Allen, R. D., J. D. Marshall, J. B. Roths, and C. L. Sidman. 1990. Differences defined by bone marrow transplantation suggest that lpr and gld are mutations of genes encoding an interacting pair of molecules. J. Exp. Med. 172:13671375.

10. Cohen, P. L., and R. A. Eisenberg. 1991. lpr and gld: single gene models of systemic autoimmunity and lymphoproliferative disease. Annu. Rev. Immunol. 9:243-269.

11. Sneller, M. C., S. E. Straus, E. S. Jaffe, J. S. Jaffe, T. A. Fleisher, M. Stetler-Stevenson, and W. Strober. 1992. A novel lymphoproliferative/autoimmune syndrome resembling murine lpr/gld disease. J. Clin. Invest. 90:334-341.

12. Shivakumar, S., G. C. Tsokos, and S. K. Datta. 1989. T cell receptor $\alpha / \beta$ expressing double-negative $\left(\mathrm{CD}^{-} / \mathrm{CD}^{-}\right)$and $\mathrm{CD} 4^{+} \mathrm{T}$ helper cells in humans augment the production of pathogenic anti-DNA autoantibodies associated with lupus nephritis. J. Immunol. 143:103-112.

13. Warren, R. F., S. A. Caster, J. B. Roths, E. D. Murphy, and D. S. Pisetsky. 1984. The influence of the lpr gene on B cell activation: differential antibody expression in lpr congenic mouse strains. Clin. Immunol. Immunopathol. 31:6577. 
14. Carlsten, H., and A. Tarkowski. 1989. Expression of heterozygous lpr gene in MRL mice. Scand. J. Immunol. 30:457-462.

15. Tan, E. M., A. S. Cohen, J. F. Fries, A. T. Masi, D. J. McShane, N. F Rothfield, J. G. Schaller, N. Talal, and R. J. Winchester. 1982. The 1982 revised criteria for the classification of systemic lupus erythematosus. Arthritis Rheum. 25:1271-1277.

16. Arnett, F. C., S. M. Edsworth, D. A. Bloch, D. J. McShane, J. F. Fries, N. S. Cooper, L. A. Healey, S. R. Kaplan, M. H. Liang, H. S. Luthra et al. 1988 The American Rheumatism Association 1987 revised criteria for the classification of rheumatoid arthritis. Arthritis Rheum. 31:315-324.

17. Bini, P., J.-L. Chu, C. Okolo, and K. Elkon. 1990. Analysis of autoantibodies to recombinant La (SS-B) peptides in systemic lupus erythematosus and primary Sjögren's syndrome. J. Clin. Invest. 85:325-333.

18. Bombardier, C., D. Gladman, M. Urowitz, D. Caron, C. Chang, and the Committee on Prognosis Studies in SLE. 1992. Derivation of the SLEDAI. A disease activity index for lupus patients. Arthritis Rheum. 35:630-640.

19. Ashany, D., J. Hines, A. Gharavi, J. Mouradian, and K. B. Elkon. 1992. Analysis of autoantibody production in SCID-SLE chimeras. Clin. Exp. Immunol. 88:84-90.

20. Reinherz, E. L., R. E. Hussey, and S. F. Schlossman. 1980. A monoclonal antibody blocking human T cell function. Eur. J. Immunol. 10:758-762.

21. Takeuchi, T., C. E. Rudd, S. F. Schlossman, and C. Morimoto. 1987. Induction of suppression following autologous mixed lymphocyte reaction: role for a novel 2H4 antigen. Eur. J. Immunol. 17:97-103.

22. Morimoto, C., N. L. Letvin, A. W. Boyd, M. Hagan, H. M. Kornacki, and S. F. Schlossman. 1985. The isolation and characterization of the human helper inducer T cell subset. J. Immunol. 134:3762-3769.

23. Nadler, L. M., K. C. Anderson, G. Marti, M. Bates, E. Park, J. F. Daley, and S. F. Schlossman. 1983. B4, a human B lymphocyte associated antigen expressed on normal, mitogen activated and malignant B lymphocytes. J. Immunol. 131:244-250.

24. Evans, R. L., D. W. Wall, C. D. Platsoucas, F. P. Siegal, S. M. Fikrig, C. M Testa, and R. A. Good. 1981. Thymus-dependent membrane antigen in man: inhibition of cell-mediated lympholysis by monoclonal antibodies to the $T_{H 2}$ antigen. Proc. Natl. Acad. Sci. USA 78:544-548.

25. Crow, M. K., J. A. Jover, and S. M. Friedman. 1986. Direct T helper-B cell interaction induce an early B cell activation antigen. J. Exp. Med. 164:1760 1772.

26. Mapara, M. Y., R. Bargou, C. Zugck, H. Dohner, F. Ustaoglu, R. R. Jonker, P. H. Krammer, and B. Dorken. 1993. APO-1 mediated apoptosis or proliferation in human chronic B lymphocytic leukemia: correlation with bcl-2 oncogene expression. Eur. J. Immunol. 23:702-708.

27. Dhein, J., P. T. Daniel, B. C. Trauth, A. Oehm, P. Moller, and P. H. Krammer. 1992. Induction of apoptosis by monoclonal antibody anti-APOclass switch variants is dependent on cross-linking of APO-1 cell surface antigens. J. Immunol. 149:3166-3173.

28. Wyllie, A. H., and R. G. Morris. 1982. Hormone-induced cell death
Purification and properties of thymocytes undergoing apoptosis after glucocorticoid treatment. Am. J. Pathol. 109:78-87.

29. Klas, C., K. M. Debatin, R. Jonker, and P. H. Krammer. 1993. Activation interferes with the APO-1 pathway in mature T cells. Int. Immunol. 5:625-630.

30. Elkon, K. B. 1994. Autoantibodies in SLE. In Textbook of Rheumatology. P. A. Dieppe and J. H. Klippel, editors. Mosby Publishing, London. 1-10.

31. Cerottini, J.-C., and H. R. MacDonald. 1989. The cellular basis of T cell memory. Annu. Rev. Immunol. 7:77-89.

32. Horwitz, D. A. 1993. Systemic Lupus Erythematosus: generalized autoimmunity arising from disordered immune regulation. In Arthritis and Allied Conditions. A Textbook of Rheumatology. D. J. McCarty and W. J. Koopman, editors. Lea \& Febiger, Philadelphia. 1185-1199.

33. Miyakawa, T., T. Uehara, R. Nibu, T. Tsuji, A. Yachie, S. Yonehara, and N. Taniguchi. 1992. Differential expression of apoptosis-related Fas antigen on lymphocyte subpopulations in human peripheral blood. J. Immunol. 149:37533758.

34. Koide, J. 1985. Functional property of la-positive $\mathrm{T}$ cells in peripheral blood from patients with systemic lupus erythematosus. Scand. J. Immunol. 22:577-584.

35. Raziuddin, S., H. B. Danial, and M. Kelley. 1988. OKT4 ${ }^{+} \mathrm{T}$ cell abnormality in patients with systemic lupus erythematosus: HLA-DR antigen expres sions. Clin. Immunol. Immunopathol. 48:42-49.

36. Rouvier, E., M.-F. Luciani, and P. Golstein. 1993. Fas involvement in $\mathrm{Ca}^{2+}$-independent T cell-mediated cytotoxicity. J. Exp. Med. 177:195-200.

37. Linker-Israeli, M., F. P. Quismorio, Jr., and D. A. Horwitz. 1990. CD8+ lymphocytes from patients with systemic lupus erythematosus sustain, rather than suppress, spontaneous polyclonal IgG production and synergize with CD4 ${ }^{+}$ cells to support autoantibody synthesis. Arthritis Rheum. 33:1216-1225.

38. Kammer, G. M., and R. L. Stein. 1990. T lymphocyte immune dysfunctions in systemic lupus erythematosus. J. Lab. Clin. Med. 115:273-282.

39. Koide, J., M. Takano, T. Takeuchi, O. Hosono, K. Amano, M. Homma, and T. Abe. 1986. Direct demonstration of $T$ cell defects in patients with systemic lupus erythematosus. Scand. J. Immunol. 23:449-459.

40. Groux, H., G. Torpier, D. Monté, Y. Mouton, A. Capron, and J. C. Ameisen. 1992. Activation-induced death by apoptosis in $\mathrm{CD}^{+} \mathrm{T}$ cells from human immunodeficiency virus-infected asymptomatic individuals. J. Exp Med. 175:331-340.

41. Meyaard, L., S. A. Otto, R. R. Jonker, M. J. Mijnster, R. P. M. Keet, and F. Miedema. 1992. Programmed death of T cells in HIV infection. Science (Wash. DC). 257:217-219.

42. Hashimoto, S., A. Ishi, and S. Yonehara. 1991. The Elb oncogene of adenovirus confers cellular resistance to cytotoxicity of tumor necrosis factor and monoclonal anti-Fas antibody. Int. Immunol. 3:343-351.

43. Carson, D. A., and J. R. Ribeiro. 1993. Apoptosis and disease. Lancet. 341:1251-1254.

44. Chu, J.-L., J. Drappa, A. Parnassa, and K. B. Elkon. 1993. The defect in Fas mRNA expression in MRL/lpr mice is associated with insertion of the retrotransposon, ETn. J. Exp. Med. 178:723-730. 